\title{
A Data Envelopment Analysis Approach to Performance Efficiency of Intellectual Capital - Case of Titan Company Limited"
}

\author{
Deepa Venugopal ${ }^{1 *}$, S. Thirupparkadal Nambi ${ }^{2}$ and M. Lakshmanan ${ }^{3}$ \\ ${ }^{1}$ Associate Professor, DJ Academy for Managerial Excellence, Coimbatore - 641032, Tamil Nadu, India \\ ${ }^{2}$ Professor, DJ Academy for Managerial Excellence, Coimbatore - 641032, Tamil Nadu, India \\ ${ }^{3}$ Student, DJ Academy for Managerial Excellence, Coimbatore - 641032, Tamil Nadu, India
}

\section{Abstract}

The purpose of this paper is to value the Performance efficiency of Intellectual Capital (IC) on Financial performance indicators of Titan Company Limited. Data required for analysis were collected from the Annual reports of the company for a period of twenty years. This study uses a DEA - CCR - Output Model which consist of intellectual capital indices as input and financial performance measures as output. Results of the efficiency analysis reveals that of the 20 years studied, only 6 years $(2007,2011,2012,2013,2015$, and 2016) were found to be the best performing years in terms of harnessing the goodness of intellectual capital. Some years were very close to perfect efficiency score of one, but the rest of the years showed very poor utilisation of intellectual capital to impact financial performance.

Keywords: Intellectual Capital Efficiency, VAIC ${ }^{\mathrm{TM}}$, Value Addition, DEA, Efficiency Scores, Efficiency Frontier

\section{Introduction}

There has been a drastic shift and astronomical transformation in competition and industrial outlook in the past two decades. Knowledge has become the quintessential capital and organizations are conscious of the fact that efficacy of knowledge derived from individuals and organisation play a vital role in sustaining competitive advantage. Knowledge age has given birth to a new class of core assets like employee's knowledge and their skills, processes in organisation, customer relationship, social responsibility, organisational structure, patents, trademark, trade secret etc. This new class of collective assets can be termed as intellectual capital. Botnis (1999) Feiwal (1975) advocate that Intellectual capital is just more than "pure intellect" but incorporating some degree of "intellectual action".
Firms that think ahead of the game realise that investing in Intellectual capital assets can help improve their competencies, create high value products, boost efficiency and drive value in the organisation. It is for the same reason that academicians, investors, businessmen, practitioners, government, and consultants find a profound interest in the study of intellectual capital. Productivity and Performance Efficiency Analysis is a slowly but strongly emerging academic sub-discipline. Measurement of efficiency helps decision - makers to improvise the existing business models and provide better working environment. Optimizing the efficiency of intellectual capital assets can go a long way in improving the performance and thereby create competitive advantage for the firms.

*Email: deepa.v@djacademy.ac.in \#This is the revised and modified version of the article, presented in the $6^{\text {th }}$ International Conference on Emerging Trends in Finance, Accounting and Banking, SDMIMD, August 2017. 
This paper is an earnest attempt to value the Intellectual capital efficiency of Titan Company limited. Most studies revolve around the corporate performance analysis. This study looks at the performance efficiency from a novel perspective. Titan company is one of the most respected engineering companies in India and owns many powerful brands like Titan watches, Tanishque, Titan-eye, Gold plus etc. It is the fifth largest integrated own brand manufacturer in the world.

Due to the growing impetus on intellectual capital in enhancing firm performance the researcher is motivated to study the potential of Titan company in terms of tacking intellectual capital to improve financial performance. This is one of those aboriginal studies interlacing Intellectual Capital Valuation VAIC ${ }^{\mathrm{TM}}$ and DEA in the Indian context. The aim is to measure intellectual capital and financial performance efficiency for a period of twenty years from 1997 to 2016 .

\section{Review of Literature}

\subsection{Intellectual Capital}

Intellectual capital can be defined as intellectual resources that have been "formalized, captured and leveraged" to create assets of higher value (Prusak, 1998). According to Thomas Stewart "intellectual capital is something that cannot be touched, although it slowly makes you rich".

Studies on IC were conducted in late 80's and Itami (1987) noted that there were differences in performance of firms. Edvinson, Skandia, Sullivan (1996) define IC as knowledge that can be converted into value. (Botnis, 1996; Edvinsson and Sullivan, 1996; Prusak, 1998; Stewart, 1991 and 1995) is of the view that identifying, valuing, reporting and managing of IC assets are crucial for maintaining competitive advantage. Brooking (1997, p.13) identifies IC as "market assets", "human centred assets", "intellectual property assets" and "infrastructure assets", which when combined with organizations other productive resources will eventually lead to value creation.

Edvinson and Malone (1997) views that intellectual capital is made up of Human capital and Structural capital. Pulic's approach uses human capital (VAHU), Physical Capital (VACA) and structural capital (STVA) to measure the Intellectual ability of a company. To put it short, intellectual capital lacks physical form; It cannot exist on its own, but derives value from network effect, it is a claim on future assets.

\subsection{Empirical Evidence on IC and Corporate Performance}

Bornemann (1999) found a correlation between intellectual potential and economic performance on investigating Australian industries. Firer and Williams (2003) used VAICTM to measure the relationship between IC and traditional measures of corporate performance for a sample of 75 publicly traded South African Companies but failed to establish any relationship between IC and financial performance.

Business Efficiency consulting (2002) conducted an efficiency analysis on 20 counties in Croatia and found that only four counties performed more efficiently than Croatian national average, Sofian et.al., (2005) in his study reveals that IC has a countable influence on corporate performance. In an exploratory study conducted by Mohiuddin et.al., (2006) on Bangladesh's commercial banks discloses that human capital impacts the financial performance than other constituents of intellectual capital. Mavridis and Kyrmizoglou (2005) studied the efficiency of Greek banks and found that human capital impacts the performance than physical capital. Costa (2012) used DEA technique to evaluate the productivity and efficiency of Intellectual capital of 17 companies. This study helped in segregating companies based on growth and competitiveness.

In this study authors use VAIC ${ }^{\mathrm{TM}}$ method to measure IC and DEA - CCR output model to study the efficiency of IC in impacting financial performance.

\section{Methodology}

Investigation into measuring the intellectual capital and its ability to enhance profitability has always been a matter of great research interest. Continuous measurement of intellectual capital will help companies in reworking strategies, improve competencies and 
reinforce growth. There are multifarious approaches to measure Intellectual capital. Many are popular, some are expensive and some are laborious.

This study uses Value Added Intellectual Capital VAIC $^{\mathrm{TM}}$ put forth by Ante Pulic to measure Intellectual capital efficiency. This method is highly - sought after, direct and easy to use. Kujansivu and Lonnqvist (2007), opined that the strength of VAICTM method is the ability to measure the financial performance of IC within an organization thus helping in comparison Zeghal and Maaloul (2010) studied around 300 UK companies using VAIC $^{\text {TM }}$ as an indicator of firm performance. (Venugopal D, Subha, 2012) using VAIC ${ }^{\mathrm{TM}}$ found that IC impacts financial performance in Indian software Industry.

Pulic (2000) adopts this method to measure the efficiency of key resources. This method provides a paradigm shift in valuation by moving out of the traditional approach of cost controlling to value creation. VAIC ${ }^{\mathrm{TM}}$ focuses on the efficiency of three types of inputs which include Physical Capital efficiency - ACA, Human Capital efficiency - VAHU and Structural Capital efficiency - STVA. VAIC ${ }^{\mathrm{TM}}$ is sum of these above said efficiencies making it Intellectual capital efficiency.

\subsection{Calculation}

$\mathrm{VAIC}^{(\mathrm{TM})}$ starts with finding out the value creating efficiency of the organization which is written as VA.

$$
\mathrm{VA}=\mathrm{OUT}-\mathrm{IN} \text { (output }- \text { input) }
$$

$\mathrm{VA}=$ interest expense + depreciation + dividend + corporate taxes + equity of minority shareholders in the net income of subsidiaries + retained profits + sum of wages and salaries of the company

The next step is to find out the VACA - which is the Value Added physical capital

This looks at the value creation ability of capital expended. Here net assets are considered.

$$
\mathrm{VACA}=\mathrm{VA} / \mathrm{CA}
$$

Thus, VACA becomes the intellectual ability of the companies to harness physical capital
The next step is to find out the relationship of human capital with value creation

$\mathrm{VAHC}=\mathrm{VA} / \mathrm{HC}$

It indicates the quality of Human resources and their ability to create value. HC is the sum of all the wages and salaries

In the last part, Structural capital - SC coefficient measures the amount of SC needed to create value addition VA. SC calculation works in the reverse proportion when compared to physical capital and Human capital.

$$
\begin{aligned}
& \mathrm{SC}=\mathrm{VA}-\mathrm{HC} \\
& \mathrm{STVA}=\mathrm{SC} / \mathrm{VA}
\end{aligned}
$$

Finally, VAIC ${ }^{(\mathrm{TM})}$ looks at the Intellectual capital value creation in whole and in pieces by the following formula

$$
\text { VAIC }^{(\mathrm{TM})}=\mathrm{VACA}+\mathrm{VAHU}+\mathrm{STVA}
$$

Valuation of financial performance is done using proxy measures which have got literature support. Proxy variables used are ROA, ROE, EPS and MCAP

ROA shows the efficiency in using the assets to enhance the earnings

$$
\begin{aligned}
& \mathrm{ROA}=\text { Income available to equity } \\
& \text { shareholders/ Total Assets }
\end{aligned}
$$

ROE measures that efficiency of the firm to generate growth from amount invested;

It is one of the important financial ratios also known as Return on Net worth (RONW)

$$
\text { ROE }=\text { Net Income /Shareholders equity }
$$

EPS is a measure of company's profitability and is the single most factor which determines the price of shares.

$$
\begin{aligned}
& \text { EPS= Income available to equity } \\
& \text { shareholders/Average Outstanding Shares }
\end{aligned}
$$

Market capitalisation is a figure used to determine the company's size. It is of great interest to investor community and is a good indicator of risk taken up by the organisation. 
Market Capitalisation $=$ Average

outstanding shares * current market price

\subsection{Data Envelopment Analysis - DEA}

Data envelopment analysis (DEA) is a widely used optimization technique for evaluating the efficiencies of homogenous decision-making units. It is a non-parametric method and is no prior assumption about data of its underlying forms to relate input to output or to other variables in DEA. This technique was originally developed by Chames, Cooper and Rhodes (1978) to evaluate non-profit and public-sector organizations. Efficiency, in its simplest form can be defined as the ratio of output to input. But a typical decision-making unit will have multiple inputs and outputs and hence its efficiency can be defined as

$$
\frac{\text { weighted sum of outputs }}{\text { weighted sum of inputs }}=\frac{\sum_{k} u_{k} y_{k g}}{\sum_{j} u_{j} y_{j g}}
$$

where $v_{\mathrm{j}}(\mathrm{j}=1,2, \ldots, m)$ is the weight assigned to the $j^{\text {th }}$ input and $u_{\mathrm{k}}(\mathrm{k}=1,2, \ldots, r)$ is the weight of the $k \mathrm{t}^{\mathrm{h}}$ output. The evaluation of the efficiency of the unit $U_{q}$ consists of maximizing its efficiency score under the constraints that the efficiency scores of all other units cannot be greater than 1 or $100 \%$. Such an optimisation model can be formulated as follows:

$$
\begin{aligned}
& \operatorname{maximum}=\frac{\sum_{k} u_{k} y_{k g}}{\sum_{j} u_{j} y_{j g}} \\
& \text { subject to }=\frac{\sum_{k} u_{k} y_{k g}}{\sum_{j} u_{j} y_{j g}}<1, \quad p=1,2 \ldots, n \\
& u_{i} \geq \varepsilon, \quad i=1,2, \ldots, r \\
& v_{i} \geq \varepsilon, \quad j=1,2, \ldots, m
\end{aligned}
$$

The above model is a primal CCR model. To reduce the complexities involved with the computation, it would be more efficient to work with the corresponding dual form which is given below

$$
\text { minimize } \mathrm{z}=\theta-\varepsilon\left(\sum_{k=1}^{n} S_{k}^{+}\right.
$$

$$
\begin{array}{cc}
\text { Subject to } \sum_{k=1}^{n} \lambda_{j} x_{i j} S_{i}^{-}=\theta x_{i j} & i=1,2, \ldots, m \\
\sum_{j=1}^{n} \lambda_{j} y_{k j}=y_{k q} & k=1,2, \ldots, r \\
\lambda_{j} \geq 0, s_{k}^{+}>0, s_{i}^{-} \geq 0 &
\end{array}
$$

where $\lambda=\left(\lambda_{1}, \lambda_{2}, \ldots, \lambda_{\mathrm{n}}\right), \lambda \geq 0$, are the weights assigned to the evaluated units, $\mathbf{s}^{+}$and $\mathbf{s}^{-}$are vectors of positive and negative slacks in input and output constraints, $\varepsilon$ is an infinitesimal constant and $\theta$ is a scalar variable expressing the reduction rate of inputs to reach the efficient frontier. The unit $U_{q}$ is said to be efficient only if the optimum value of the variable $\theta^{*}$ is equal to 1 and the optimum values of all slacks $\mathbf{s}^{+}$and $\mathbf{s}^{-}$is equal to zero.

Along with the efficiency score $\theta^{*}$, the DEA models compute inputs and outputs of the so-called virtual units. This unit lies always on the efficient frontier and expresses how to improve inputs/outputs of the evaluated unit to reach the efficient frontier. The virtual units corresponding to the units identified as efficient by a DEA model are identical because the efficient units lie on the frontier. The virtual units corresponding to nonefficient units can be expressed as follows

$$
\begin{aligned}
& x_{i q}^{\prime}=\theta^{*} x_{i q}-s_{i}^{-}, \quad i=1,2, \ldots, m \\
& y_{k q}^{\prime}=y_{k q}+s_{k}^{+}, \quad k=1,2, \ldots, r
\end{aligned}
$$

The variable $\mathrm{s}^{+}$and $\mathrm{s}^{-}$are the slack variable expressing the difference between virtual inputs/outputs and the appropriate inputs/outputs of the unit $\mathrm{U}_{\mathrm{q}}$. The above equation is for input oriented DEA model and the aim of this model is to find how to reduce the inputs of nonefficient units to reach the efficient frontier. This model can be further formulated to make it suitable for output oriented model as well.

\subsection{Data Source and Sample}

Data for the study was collected from the annual reports of Titan company and from National Stock Exchange website. A longitudinal data covering twenty years from 1997 to 2016 were taken for study. Last two decades has been eventful for Titan company. Hence 
the researcher believes that twenty-year study would be more rigorous and conclusive.

\section{Empirical Analysis and Discussion}

CCR - Output oriented model has been used in this study. The output oriented models look at efficiency ratios in a different way. Here reciprocal ratios are used where output is divided by input. This is the essence and distinguishing feature of output oriented models from input oriented DEA models. The input consists of variables which measure intellectual capital performance by VAIC ${ }^{\mathrm{TM}}$ and the output variables are Proxy financial performance variables which capture a firm's financial performance. The decision-making units (DMU) used for this study are "Years" of study. Thus, each year is considered as a Decision-Making Unit DMU.

\subsection{Results and Interpretation of Output- Oriented - CCR (CRS)}

In Table - 4.1 reports the efficiency ranks and scores of the DMU. A four input and four output models has been used in this study and results show that 6 out of the 20 years taken for study are efficient and the rest of the years are inefficient. Those years which have an efficiency score equal to 1 are considered efficient and others which are having efficiency scores less than 1 but greater than zero are considered inefficient. Hence years 2007, 2011, 2012, 2013, 2015, 2016 are considered efficient with scores equal to 1 . The ranking below differentiates efficient and inefficient years.

\section{Ranking of DMU - Years based on Performance Efficiency}

Table 4.1. Ranking of Decision Making Units in terms of their efficiency Scores

\begin{tabular}{|c|c|c|}
\hline DMU & Score & Rank \\
\hline 2007 & 1 & 1 \\
\hline 2011 & 1 & 1 \\
\hline 2012 & 1 & 1 \\
\hline 2013 & 1 & 1 \\
\hline 2015 & 1 & 1 \\
\hline 2016 & 1 & 1 \\
\hline
\end{tabular}

\begin{tabular}{|c|c|c|}
\hline 2006 & 0.9842 & 7 \\
\hline 2008 & 0.9768 & 8 \\
\hline 2014 & 0.975 & 9 \\
\hline 2010 & 0.9739 & 10 \\
\hline 2009 & 0.9149 & 11 \\
\hline 2005 & 0.8366 & 12 \\
\hline 2004 & 0.6793 & 13 \\
\hline 2001 & 0.6556 & 14 \\
\hline 1997 & 0.6286 & 15 \\
\hline 2003 & 0.5625 & 16 \\
\hline 2002 & 0.5308 & 17 \\
\hline 1999 & 0.5015 & 18 \\
\hline 2000 & 0.4823 & 19 \\
\hline 1998 & 0.4788 & 20 \\
\hline
\end{tabular}

\subsection{Efficiency Report for Output Oriented CCR Model}

$1 /$ Score in the efficiency report shows the mirror ratios or reciprocal ratios in the out-put oriented model. Any score above 1 in the 1 score column shows inefficiency. Years which are considered inefficient can improve their efficiency or reduce their inefficiency by increasing the output. For e.g. consider the following years, 1997, 1998, 2010, 2014 etc... In case of 1997 the output efficiency should be increased by $59 \%$, 1998 by $108 \%$ to achieve full efficiency. Looking at 2010 and 2014 figures we may conclude that they were years very close to efficiency frontier. 2010 needs to improve their efficiency by $2.67 \%$ and 2014 by $2.56 \%$ respectively. The same can be applied for other years also. This efficiency report helps us in finding out what possible increase in financial performance could have led to the full and efficient utilization of the money/ resources like human capital, physical capital, structural capital and overall intellectual capital.

Table 4.2. Efficiency Report for Output oriented CCR model

\begin{tabular}{|l|l|l|l|l|l|}
\hline No. & DMU & Score & Rank & $1 /$ score & $\begin{array}{l}\% \\
\text { increase }\end{array}$ \\
\hline 1 & 1997 & 0.6286 & 15 & 1.590837 & 59.08368 \\
\hline 2 & 1998 & 0.4788 & 20 & 2.088555 & 108.8555 \\
\hline 3 & 1999 & 0.5015 & 18 & 1.994018 & 99.40179 \\
\hline 4 & 2000 & 0.4823 & 19 & 2.073398 & 107.3398 \\
\hline 5 & 2001 & 0.6556 & 14 & 1.52532 & 52.53203 \\
\hline 6 & 2002 & 0.5308 & 17 & 1.883949 & 88.39488 \\
\hline 7 & 2003 & 0.5625 & 16 & 1.777778 & 77.77778 \\
\hline 8 & 2004 & 0.6793 & 13 & 1.472104 & 47.21036 \\
\hline
\end{tabular}




\begin{tabular}{|c|c|c|c|c|c|}
\hline 9 & 2005 & 0.8366 & 12 & 1.195314 & 19.53144 \\
\hline 10 & 2006 & 0.9842 & 7 & 1.016054 & 1.605365 \\
\hline 11 & 2007 & 1 & 1 & 1 & 0 \\
\hline 12 & 2008 & 0.9768 & 8 & 1.023751 & 2.375102 \\
\hline 13 & 2009 & 0.9149 & 11 & 1.093016 & 9.301563 \\
\hline 14 & 2010 & 0.9739 & 10 & 1.026799 & 2.679947 \\
\hline 15 & 2011 & 1 & 1 & 1 & 0 \\
\hline 16 & 2012 & 1 & 1 & 1 & 0 \\
\hline 17 & 2013 & 1 & 1 & 1 & 0 \\
\hline 18 & 2014 & 0.975 & 9 & 1.025641 & 2.564103 \\
\hline 19 & 2015 & 1 & 1 & 1 & 0 \\
\hline 20 & 2016 & 1 & 1 & 1 & 0 \\
\hline
\end{tabular}

\subsection{Slacks}

"Slacks" represent the leftover of inefficiencies and would be found only for those years which are inefficient. Efficient years have " 0 " slack. The leftover portion of inefficiencies - or slack can push the inefficient DMU's to the efficient frontier. The mathematical formulation of slack is given in the previous session.

It is evident from the Table 4.3 given below that all efficient years have a Zero slack. Year 2014 requires an increase in ROA by .065 and EPS by .418 . Despite increasing the output proportionately by the efficiency score it could still not achieve full efficiency and no more increase of other outputs are possible. Hence a proportionate reduction in human capital and structural capital is required to lift that year to efficient frontier. The same explanation is applicable for other years also. This reveals that even with less spent on human and structural capital greater efficiency is possible in financial performance.

Table 4.3. Slack of Output Oriented CCR model

\begin{tabular}{|c|c|c|c|c|c|c|c|c|c|c|c|}
\hline No. & DMU & Score & Rank & VACA & VAHU & STVA & VAIC & ROE & ROA & MCAP & EPS \\
\hline 1 & 1997 & 0.6286 & 15 & 0 & 0.583 & 0.149 & 0.732 & 0 & 0.199 & 0.239 & 3.688 \\
\hline 2 & 1998 & 0.4788 & 20 & 0 & 0.106 & 0.012 & 0.118 & 0 & 0.158 & 0 & 6.541 \\
\hline 3 & 1999 & 0.5015 & 18 & 0 & 0.022 & 0 & 0.022 & 0 & 0.153 & 0 & 5.817 \\
\hline 4 & 2000 & 0.4823 & 19 & 0.043 & 0 & 0 & 0.043 & 0 & 0.164 & 0 & 25.529 \\
\hline 5 & 2001 & 0.6556 & 14 & 0 & 0 & 0.035 & 0.035 & 0 & 0.157 & 0 & 26.601 \\
\hline 6 & 2002 & 0.5308 & 17 & 0.093 & 0 & 0.013 & 0.106 & 0.025 & 0.129 & 0 & 2.744 \\
\hline 7 & 2003 & 0.5625 & 16 & 0.045 & 0 & 0.014 & 0.059 & 0.105 & 0.15 & 0 & 5.867 \\
\hline 8 & 2004 & 0.6793 & 13 & 0.132 & 0 & 0.014 & 0.146 & 0.058 & 0.124 & 0 & 3.57 \\
\hline 9 & 2005 & 0.8366 & 12 & 0.165 & 0 & 0.013 & 0.178 & 0 & 0.091 & 0 & 1.456 \\
\hline 10 & 2006 & 0.9842 & 7 & 0 & 0 & 0.031 & 0.031 & 0 & 0.144 & 0 & 46.448 \\
\hline 11 & 2007 & 1 & 1 & 0 & 0 & 0 & 0 & 0 & 0 & 0 & 0 \\
\hline 12 & 2008 & 0.9768 & 8 & 0.143 & 0 & 0.024 & 0.167 & 0 & 0.103 & 0 & 37.624 \\
\hline 13 & 2009 & 0.9149 & 11 & 0.143 & 0 & 0.005 & 0.148 & 0 & 0 & 0 & 2.205 \\
\hline 14 & 2010 & 0.9739 & 10 & 0.063 & 0 & 0.006 & 0.069 & 0 & 0 & 0 & 8.283 \\
\hline 15 & 2011 & 1 & 1 & 0 & 0 & 0 & 0 & 0 & 0 & 0 & 0 \\
\hline
\end{tabular}

\begin{tabular}{|c|c|c|c|c|c|c|c|c|c|c|c|}
\hline 15 & 2011 & 1 & 1 & 0 & 0 & 0 & 0 & 0 & 0 & 0 & 0 \\
\hline 16 & 2012 & 1 & 1 & 0 & 0 & 0 & 0 & 0 & 0 & 0 & 0 \\
\hline 17 & 2013 & 1 & 1 & 0 & 0 & 0 & 0 & 0 & 0 & 0 & 0 \\
\hline 18 & 2014 & 0.975 & 9 & 0 & 0.087 & 0.003 & 0.09 & 0 & 0.065 & 0 & 0.418 \\
\hline 19 & 2015 & 1 & 1 & 0 & 0 & 0 & 0 & 0 & 0 & 0 & 0 \\
\hline 20 & 2016 & 1 & 1 & 0 & 0 & 0 & 0 & 0 & 0 & 0 & 0 \\
\hline
\end{tabular}

\subsection{Benchmark for Output Oriented CCR Model}

The Efficient DMU's -years under study in the output oriented model consider themselves as benchmarks. Thus, the benchmark for 2007 is 2007, 2011 is 2011, 2012 is 2012, 2013 is 2013 and so on. Benchmarked years have been highlighted in Table -4.4 given below.

Table 4.4. Benchmarks for the model

\begin{tabular}{|c|c|c|c|c|c|c|c|c|c|}
\hline No. & DMU & Score & Rank & \multicolumn{7}{|c|}{ Reference $(\lambda)$ values } \\
\hline 1 & 1997 & 0.6286 & 15 & 2012 & 0.755 & & & & \\
\hline 2 & 1998 & 0.4788 & 20 & 2015 & 0.436 & 2016 & 0.588 & & \\
\hline 3 & 1999 & 0.5015 & 18 & 2012 & 0.032 & 2015 & 0.138 & 2016 & 0.857 \\
\hline 4 & 2000 & 0.4823 & 19 & 2007 & 0.146 & 2011 & 0.189 & 2016 & 0.677 \\
\hline 5 & 2001 & 0.6556 & 14 & 2011 & 0.247 & 2015 & 0.203 & 2016 & 0.321 \\
\hline 6 & 2002 & 0.5308 & 17 & 2016 & 0.892 & & & & \\
\hline 7 & 2003 & 0.5625 & 16 & 2016 & 0.883 & & & & \\
\hline 8 & 2004 & 0.6793 & 13 & 2016 & 0.804 & & & & \\
\hline 9 & 2005 & 0.8366 & 12 & 2007 & 0.103 & 2016 & 0.707 & & \\
\hline 10 & 2006 & 0.9842 & 7 & 2007 & 0.208 & 2011 & 0.606 & 2016 & 0.037 \\
\hline 11 & 2007 & 1 & 1 & 2007 & 1 & & & & \\
\hline 12 & 2008 & 0.9768 & 8 & 2007 & 0.203 & 2011 & 0.701 & & \\
\hline 13 & 2009 & 0.9149 & 11 & 2007 & 0.6 & 2011 & 0.286 & 2016 & 0.113 \\
\hline 14 & 2010 & 0.9739 & 10 & 2007 & 0.236 & 2011 & 0.62 & 2016 & 0.136 \\
\hline 15 & 2011 & 1 & 1 & 2011 & 1 & & & & \\
\hline 16 & 2012 & 1 & 1 & 2012 & 1 & & & & \\
\hline 17 & 2013 & 1 & 1 & 2013 & 1 & & & & \\
\hline 18 & 2014 & 0.975 & 9 & 2012 & 0.192 & 2015 & 0.828 & & \\
\hline 19 & 2015 & 1 & 1 & 2015 & 1 & & & & \\
\hline 20 & 2016 & 1 & 1 & 2016 & 1 & & & & \\
\hline
\end{tabular}

However, for performance inefficient years, the benchmarks are one or many of the efficiently performing years. For example, the benchmark for 2014 is both 2012 and 2015 note that both 2012 and 2015 are efficient. It is also evident that year 2014 is very close to efficiency with a score of 0.975 . We can assume that the proportionate increase in output was achieved in the following year i.e., in 2015 and hence moved to the efficiency frontier. 
For the years 2006, 2008, 2009, 2010, the benchmarked years are same -2007 and 2011. The values of $\lambda$ weights near to the benchmarked years (in case of inefficient years) are obtained by running the dual version of LPP. Hence for example, 2014 will attempt to be more efficient like 2015 than 2012 considering these $\lambda$ weights $-\left(\lambda_{1}=.192, \lambda_{2}=.828\right)$. This is proven by the fact that 2015 became a benchmarked efficient year.

\section{Conclusion}

This study aims at measuring the intellectual capital using VAIC ${ }^{\mathrm{TM}}$ and its performance efficiency with respect to financial performance. Performance efficiency is analysed using DEA which is a specialized form of linear programming. It looks at exposte analysis of empirical performance data for any kind of DMU which transforms input into output. In the present study, the intellectual capital performance efficiency of TITAN Company Ltd has been considered. The DMU's are "years" for which data is analysed. Every year is considered as a DMU and 20 years of data have been used in this study.

DEA is a non - parametric technique which allows usage of multiple inputs and outputs to derive efficiency scores for each DMU's under study. Four inputs and four outputs are used in this empirical study. The input variables studied include VAIC, VAHU, VACA AND STVA and output variables include proxy financial performance variables like ROA, ROE, EPS, MCAP. It is interesting to find that only six years $(2007,2011$, 2012, 2013, 2015, and 2016) out of the 20 years studied are fully efficient. There are some years which are very close to full efficiency. This study will be an eyeopener for a company like Titan which has pumped in huge amounts of money into research and development and brand building. Company can get cues about performance efficiency and can develop strategic plans for bettering the performance and maximising intellectual capital of the organisation. Furthermore, this investigation reveals the reasons for inefficiency too. Study highlights the combination of inputs and output that can enhance efficiency. It can be noted that there is an improvement in performance efficiency over the years of study and in the recent years we observe that com- pany has become efficient in utilisation of resources and their strategies of expanding the business with diversification and acquisitions.

Not many studies on performance efficiency have been done in India employing DEA. This study is ahead of its time by looking at Intellectual capital efficiency when this topic is burgeoning and such studies are rare in India. This study adds to the literature by employing DEA for a single company analysis. More in-house studies can be conducted extending to various departments or product lines or even brands. Studies can be extended to find the sectoral efficiencies by using advanced DEA tools.

\section{Bibliography}

Bontis, N. (1999). Managing organizational knowledge by diagnosing intellectual capital: framing and advancing the state of the field. International Journal of Technology Management, 18(5-8), 433-62.

Brooking, A. (1997). The Management of Intellectual Capital. Long Range Planning, 30(3), 364 - 355.

Chames, A. Cooper, W. W., \& Rhodes E. (1978). Measuring the efficiency of decision making units. European Journal of Operational Research, 2(6), 429-444.

Chen, M. C., Cheng, S. J., \& Hwang, Y. (2005). An empirical investigation of the relationship between intellectual capital and firms' market value and financial performance. Journal of Intellectual Capital, 6(2), 159-76.

Costa, R. (2012). Assessing Intellectual Capital Efficiency and Productivity: An application to the Italian Yacht manufacturing sector. Expert System with Applications, 39, 7255-7261.

Edvinsson, L., \& Sullivan, P. (1996). Developing a model for managing intellectual capital. European Management Journal, 14(4).

Edvinsson, L. (1997). Developing intellectual capital at Skandia. Long Range Planning, 30(3), 266-373.

Edvinsson, L. \& Malone, M. (1997). Intellectual Capital: Realizing your Company's True Value by Finding its Hidden Brainpower. Harper Collins, New York, NY.

Feiwal, G. R. (1975). The Intellectual Capital of Michal Kalecki: A Study in Economic Theory and Policy. The University of Tennessee Press, Knoxville, TN.

Firer, S., \& Williams, S. M. (2003). Intellectual capital and traditional measures of corporate performance. Journal of Intellectual Capital, 4(3), 348-60. 
Goh, P. C. (2005). Intellectual capital performance of commercial banks in Malaysia. Journal of Intellectual Capital, 6(3). 385-96

Itami, H. (1987). Mobilizing Invisible Assets. Harvard University Press, Cambridge

Kujansivu, P., \& Lonnqvist, A. (2007). Investigating the value and efficiency of intellectual capital. Journal of Intellectual Capital, 8(2). 272-87.

Maaloul, A., \& Zeghal, D. (2010). Analysing value added as an indicator of intellectual capital and its consequences on company performance. Journal of Intellectual Capital, 11(1), 39-60.

Mavridis, D., \& Kyrmizoglou, G. P. (2005). Intellectual capital performance drivers in the Greek banking sector. Management Research News, 28(5). 43-6.

Mohiuddin, M., Najibullah, S., \& Shahid, A. I. (2006). An exploratory study on intellectual capital performance of the commercial banks in Bangladesh. The Cost and Management, 34(6). 40-54.

Prusak, L. (1998). Working Knowledge: How organizations Manage What They Know. Harvard Business School Press, Cambridge, MA.
Pulic, A. (2000). An accounting tool for IC management. Available at: www.measuring-ip.at/Papers/ham99txt. htm.

Sofian, S., Tyles, M., \& Pike, R. (2005). The Implications of Intellectual Capital on Performance Measurement and Corporate Performance.

Stewart, T. A. (1997). Intellectual Capital: The Wealth of New Organizations. Nicholas Brealey Publishing, London.

Tseng, C., \& Goo, Y. J. (2005). Intellectual capital and corporate value in an emerging economy: empirical studies of Taiwanese manufacturers. $R \& D$ Management, 35(2). 187-201.

Venugopal, D. \&, Subha, M. V. (2012). Does intellectual capital create value addition? An empirical investigation into the intellectual capital performance and financial performance of Indian software industry. European Journal of Social Sciences, 33(1), 119-132.

Zeghal, D., (2000). New assets for the new economy. FMI Journal, 11(2). 35-40. (Financial Management Institute of Canada). 